\title{
Antibodies to type II and XI collagens: evidence for the formation of antigen specific as well as cross reacting antibodies in patients with rheumatoid arthritis
}

\author{
KEITH MORGAN ${ }^{1}$ CATHERINE BUCKEE, ${ }^{1}$ IAN COLLINS, \\ SHIRLEY AYAD, ROY B CLAGUE, ${ }^{2}$ AND P J LENNOX HOLT \\ From the Departments of ${ }^{1}$ Rheumatology and ${ }^{2}$ Biochemistry and Molecular Biology, University of \\ Manchester Medical School, Oxford Road, Manchester
}

SUMMARY Antigen specific and cross reacting antibodies to native and denatured types II and XI $\vec{\circ}$ collagen were detected in the sera of rats immunised with either of these antigens. The antibodies $\infty$ from rats immunised with type XI collagen initially showed the strongest binding to the $\alpha 2(\mathrm{XI})$ 윽 chain of type XI collagen but later binding to the $\alpha 3$ (XI) chain was seen. Sera from patients with rheumatoid arthritis had antibodies that bound to both type II and XI collagens. Immunoblotting $\mathbb{D}_{\mathbb{D}}$ studies showed that most patients had antibodies which bound to the $\alpha 1$ (II) chain of type II collagen and to the $\alpha 3(\mathrm{XI})$ chain of type XI collagen. Some patients also had antibodies which bound to the $\alpha 1(\mathrm{XI})$ and to the $\alpha 2(\mathrm{XI})$ chains of type XI collagen. Thus antibodies to unique ass $\stackrel{\oplus}{\sim}$ well as to common epitopes on each of the two types of collagen molecule occur in some patien $\vec{\otimes}$ with rheumatoid arthritis.

Key words: collagen induced arthritis.

Articular cartilage, which is destroyed in rheumatoid arthritis (RA), contains at least four genetically distinct collagen types: the major type II collagen and the quantitatively minor collagens, types VI, IX, and XI. ${ }^{1}$ Both type II and type XI (formerly $1 \alpha 2 \alpha 3 \alpha$ ) collagens have been shown to be arthritogenic and immunogenic in rats. ${ }^{2-5}$ Solid phase radioimmunoassay has previously shown that antibodies formed to each of these two collagens in the rat bind to the other collagen. ${ }^{5} \mathrm{~A}$ role for these antibodies in the production of collagen induced arthritis in the rat has been proposed, ${ }^{6-8}$ and anticollagen antibodies could play a part in the induction or perpetuation of inflammation in some patients with RA. Antibodies to types II, IX, and XI collagen (native and denatured) have been found in the sera of some patients with RA. ${ }^{9}$ In this paper we have investigated antibodies to types II and XI collagen in patients with RA and also in rats immunised with these collagens. We present evidence to show that antibodies to both collagens (types II

Accepted for publication 19 April 1988.

Correspondence to Dr Keith Morgan, Department of Rheumatology, University of Manchester Medical School, Stopford Building, Oxford Road, Manchester M13 9PT. and XI collagen) are formed in patients with RA, and that antibodies to type XI collagen are not solely cross reacting antibodies raised to type II collagen.

\section{Materials and methods}

COLLAGENS

Native type II collagen was extracted from bovine nasal septa by pepsin digestion and native type XI collagen from fetal bovine articular cartilage by $\delta$ similar methods. Both collagens were extensively purified by differential salt precipitation and by 은 dialysis against phosphate buffer. ${ }^{5}$ The collagens were pure by polyacrylamide gel electrophoresis and no uronic acid could be detected by the method of Bitter and Muir, ${ }^{10}$ indicating that there was no $\sigma$ proteoglycan contamination.

The collagens were lyophilised and stored at $\mathcal{N}$ $-20^{\circ} \mathrm{C}$. They were dissolved in $0.45 \mathrm{M}$ sodium chloride/0.02 M trometamol (TRIS) buffer $\mathrm{pH} 7.5$ at $2 \mathrm{mg} / \mathrm{ml}$ before use.

R A T S

Female Wistar rats (45-77 days old) were used. $\frac{7}{0}$ These rats have been inbred in an isolator for seven $\mathbb{D}$ 
generations from one original pair of non-litter mates. After weaning the rats were kept in a normal animal room used only for animals from this isolator. Similar isolator bred rats of other strains were used for some experiments. These were inbred DA rats, inbred PVG-RT1U, and DA $\times$ Wistar crosses. Sprague-Dawley rats were conventionally bred.

\section{IMMUNISATION OF RATS}

Rats were immunised intradermally on the back with $0.5 \mathrm{ml}$ of an emulsion of native bovine type II collagen $(500 \mu \mathrm{g})$ and Freund's incomplete adjuvant $(1: 1, \mathrm{v} / \mathrm{v})$ or with a similar amount of native type XI collagen. The collagens were dissolved in $0.45 \mathrm{M}$ sodium chloride/0.02 $\mathrm{M}$ trometamol buffer at $2 \mathrm{mg} / \mathrm{ml}$. The rats were given food and water freely and examined for evidence of clinical arthritis and non-articular lesions.

\section{PATIENTS}

The 46 patients were outpatients or inpatients of the rheumatology departments of the Manchester Royal Infirmary or Withington Hospital, Manchester, of the Royal Devonshire Hospital, Buxton, or of Noble's Hospital, Douglas, Isle of Man. All patients had definite or classical rheumatoid arthritis. ${ }^{11}$ As the incidence of anti-native type II collagen antibodies in patients with RA is approximately $10 \%{ }^{9}$ the patients were selected, for the likely presence of anti-type II collagen antibodies in their sera, from previous data.

\section{B L OOD S A M P ES}

Blood was collected from patients when they attended the rheumatology clinics. It was allowed to clot at room temperature and centrifuged at $1500 \mathrm{~g}$ for seven minutes. The serum was removed and frozen as aliquots at $-20^{\circ} \mathrm{C}$ until used. Control sera were obtained from 29 normal, healthy subjects attending the Regional Blood Transfusion Service.

Blood was collected from rats 14 days after immunisation with collagen or from unimmunised rats for control sera. It was treated as for the human blood.

DETECTION OF ANTICOLLAGEN ANTIBODIES

\section{Enzyme linked immunosorbent assay (ELISA)}

IgG antibodies to native and denatured types II and XI collagen were measured in the human and rat sera using a solid phase, double antibody, enzyme labelled immunoassay previously described. ${ }^{9}$ The results were expressed as arbitrary units between 0 and 1900 (maximum measurable absorbance being 2000 before subtraction of blank wells).

\section{Immunoblotting assay}

(a) Electrophoretic separation of the collagen chains. The individual chains of types XI and II collagen were separated by sodium dodecyl sulphate (SDS)polyacrylamide gel electrophoresis using a Bio-Rad Mini Protean II cell. The collagens were denatured by heating at $95^{\circ} \mathrm{C}$ for five minutes in a reducing buffer $(0.0625 \mathrm{M}$ trometamol-HC1 pH 6.8 with $2 \mathrm{M}$ urea, $0.05 \mathrm{M}$ dithiothreitol, $10 \%$ glycerol, $2 \%$ SDS, and $0.01 \%$ bromophenol blue) before electrophoresis. Aliquots $(10 \mu \mathrm{l})$ of $1.6 \mu \mathrm{g}$ of type II collagen and of $4.8 \mu \mathrm{g}$ of type XI collagen were applied to adjacent wells of a 3\% stacking gel and electrophoresed into a $4 \%$ polyacrylamide gel for 30 minutes at constant voltage (200 volts) at room temperature. This gave equal concentrations of each of the three individual $\alpha 1(\mathrm{XI}), \alpha 2(\mathrm{XI})$, and $\alpha 3(\mathrm{XI})$ chains of type XI collagen $^{12}$ with the $\alpha 1$ (II) chains of type II collagen. The gels were then equilibrated for 30 minutes at room temperature in transfer buffer (see below).

(b) Western blotting of the collagen chains. After separation as above the chains of types II and XI collagen were electrophoretically transferred from the SDS-polyacrylamide gel onto nitrocellulose according to the method of Towbin et al. ${ }^{13}$ The transfer buffer used was $25 \mathrm{mM}$ trometamol/192 mM glycine buffer $\mathrm{pH} 8.3$ containing $20 \% \mathrm{v} / \mathrm{v}$ methanol. The transfer time was 17 hours at 30 volts followed by two hours at 60 volts. After transfer the nitrocellulose membrane was cut into strips with each strip having one lane of type II collagen and one of type XI collagen. These strips were then used for the detection of anticollagen antibodies in the human or rat sera (next section).

(c) Immunodetection of anticollagen antibodies. IgG antibodies to the individual $\alpha$ chains of types II and XI collagen were detected using the nitrocellulose strips from the Western blotting. The strips were incubated at room temperature in phosphate buffered saline (PBS) (as used in the ELISA) containing $1.0 \% \mathrm{w} / \mathrm{v}$ low-fat milk and $0.5 \% \mathrm{w} / \mathrm{v}$ Tween (PBS/Tween/low fat milk) for 1.75 hours to block any remaining protein binding sites on the nitrocellulose. They were then incubated for one hour at room temperature in the appropriate serum samples, which were diluted 1:1000 in PBS/Tween/low fat milk. After washing three times with PBS/Tween they were incubated for one hour at room temperature with alkaline phosphatase labelled antihuman IgG (Dako Ltd) diluted 1:2000 or antirat IgG (Serotec Ltd) diluted 1:1000 in PBS/Tween/low fat milk. The same antibodies were used in the ELISA. After washing three times in PBS/Tween the strips were washed thoroughly in $0.15 \mathrm{M}$ veronal acetate buffer 
$\mathrm{pH} 9.6$ to remove any traces of Tween. The strips were then developed at room temperature in substrate $\mathbf{0 . 0 0 5 \%}$ of 5-bromo-4-chloroindolyl phosphate and $0.01 \%$ nitroblue tetrazolium in veronal acetate buffer with $4 \mathrm{mM}$ magnesium chloride) to detect anti-IgG bound to any anticollagen antibodies attached to the $\alpha$ chains on the membranes.

After development the strips were washed free of unreacted substrate with distilled water and dried at $37^{\circ} \mathrm{C}$ between layers of filter paper. Normal sera were always included with each batch of samples tested.

\section{Results}

\section{E L I S A}

\section{Rat sera}

Thirteen of the 15 Wistar rats immunised with native type XI collagen and four of the six rats immunised with native type II collagen developed an inflammatory arthritis 14-23 days after immunisation (median onset: 15 days for both collagens). Unimmunised rats did not develop arthritis.

Table 1 shows the mean absorbance value, standard deviation, and the upper limit of normal (mean+three standard deviations) for 10 normal Wistar rat sera and the levels of antibody in the immunised rats for native and denatured types II and XI collagen. From the ELISA results it can be seen that all the immunised rats developed antibodies to the immunising collagen and had antibodies $\square$ which bound to both its native and denatured form.? The level of antibody to the cross reacting antigen $\overrightarrow{\vec{F}}$ was, in general, very low compared with the level of antibody in rats immunised with that collagen type. $\frac{}{5}$

Thus antibodies that bound to both collagen types $\overline{\bar{n}}$ and antibodies that did not cross react were pro- $\widehat{\nabla}$ duced in these rats after immunisation with either collagen. Most of the antibodies produced were non-cross reacting and thus to epitopes specific for $\vec{\circ}$ each antigen.

\section{Human sera}

Table 2 shows the mean absorbance value, standard deviation, and the upper limit of normal $\stackrel{\oplus}{\sim}$ (mean + three standard deviations) for the 29 normal $\vec{N}$ blood donors for native and denatured types II and $\rightarrow$ XI collagen in the ELISA. Table 2 also shows the number of positive sera (out of the 46 patients) for ${ }_{\circ}^{\infty}$ each antigen and the level of antibodies for each antigen. Forty one $(89 \%)$ of the sera were positive $\vec{\square}$ for antibodies to native type II collagen, $40(87 \%)$ positive for antibodies to denatured type II, $27 \Phi$ $(59 \%)$ positive for antibodies to denatured type XIZ collagen, and only eight $(17 \%)$ positive for anti $\stackrel{\circ}{-}$ bodies to native type XI collagen. Two patients we्ge $\overrightarrow{0}$ negative for antibodies to native type II collagen $b$ w. had antibodies to denatured type II collagen. Tie level of antibody to denatured type XI in one $\overrightarrow{0}$ these patients was proportionally much higher than

Table 1 Anticollagen antibodies detected by an ELISA in the rat sera

\begin{tabular}{|c|c|c|c|c|c|c|c|c|c|}
\hline & \multicolumn{3}{|c|}{ Normals } & \multicolumn{6}{|c|}{ Positive rat sera } \\
\hline & \multirow[t]{2}{*}{ Mean } & \multirow[t]{2}{*}{$S D$} & \multirow[t]{2}{*}{$U L N^{*}$} & \multicolumn{3}{|c|}{ Type XI immunised rats $(n=15)$} & \multicolumn{3}{|c|}{ Type II immunised rats $(n=6)$} \\
\hline & & & & No & Range & Median & No & Range & Median \\
\hline Native type II collagen & $2 \cdot 1$ & 0.9 & $4 \cdot 8$ & 15 & $7-113$ & 25 & 6 & $399-1563$ & 938 \\
\hline Denatured type II collagen & $2 \cdot 9$ & $1 \cdot 0$ & $5 \cdot 9$ & 13 & $9-569$ & 35 & 6 & $874-1900$ & 1386 \\
\hline Native type XI collagen & $0 \cdot 2$ & 0.4 & 1.4 & 15 & $785-1900$ & 1653 & 6 & $2-274$ & 31 \\
\hline Denatured type XI collagen & $11 \cdot 6$ & 3.9 & $23 \cdot 3$ & 15 & $101-1432$ & 696 & 6 & $46-568$ & 114 \\
\hline
\end{tabular}

${ }^{*} \mathrm{ULN}=$ upper limit of normal-that is, mean of normals +three standard deviations.

Table 2 Anticollagen antibodies detected by an ELISA in human sera

\begin{tabular}{|c|c|c|c|c|c|c|}
\hline & \multicolumn{3}{|c|}{ Normals } & \multicolumn{3}{|c|}{ Positive patients' sera } \\
\hline & Mean & $S D$ & $U L N^{*}$ & No & Range & Median \\
\hline $\begin{array}{l}\text { Native type II collagen } \\
\text { Denatured type II collagen } \\
\text { Native type XI collagen } \\
\text { Denatured type XI collagen }\end{array}$ & $\begin{array}{r}5 \cdot 6 \\
12 \cdot 1 \\
51 \cdot 4 \\
32 \cdot 6\end{array}$ & $\begin{array}{r}5 \cdot 1 \\
10 \cdot 2 \\
36 \cdot 5 \\
22 \cdot 4\end{array}$ & $\begin{array}{r}20.9 \\
42.7 \\
160.9 \\
99 \cdot 8\end{array}$ & $\begin{array}{r}41 \\
40 \\
8 \\
27\end{array}$ & $\begin{array}{c}23-1031 \\
47-1680 \\
162-993 \\
112-1568\end{array}$ & $\begin{array}{r}79 \\
229 \\
355 \\
236\end{array}$ \\
\hline
\end{tabular}


Table 3 Binding of antibodies from rat sera to the $\alpha$ chains of types II and XI collagen detected by immunoblotting

\begin{tabular}{|c|c|c|c|c|c|c|c|c|c|c|c|c|c|c|}
\hline & \multicolumn{7}{|c|}{ Type XI immunised rats $(n=15)$} & \multicolumn{7}{|c|}{ Type II immunised rats $(n=6)$} \\
\hline & \multicolumn{5}{|c|}{ Grade* } & \multicolumn{2}{|c|}{ Total No } & \multicolumn{5}{|c|}{ Grade } & \multicolumn{2}{|c|}{ Total No } \\
\hline & 5 & 4 & 3 & 2 & 1 & $+v e$ & $-v e$ & 5 & 4 & 3 & 2 & $I$ & $+v e$ & $-v e$ \\
\hline Type II $\alpha$ chains & 0 & 0 & 0 & 0 & 0 & 0 & 15 & 0 & 0 & 0 & 2 & 4 & 6 & 0 \\
\hline Type XI $\alpha 3(\mathrm{XI})$ chain & 0 & 0 & 0 & 0 & 0 & 0 & 15 & 0 & 0 & 0 & 2 & 3 & 5 & 1 \\
\hline Type XI $\alpha 2(\mathrm{XI})$ chain & 0 & 0 & 2 & 5 & 6 & 13 & 2 & 0 & 0 & 0 & 0 & 0 & 0 & 6 \\
\hline Type XI $\alpha 1(\mathrm{XI})$ chain & 0 & 0 & 0 & 0 & 0 & 0 & 15 & 0 & 0 & 0 & 0 & 0 & 0 & 6 \\
\hline
\end{tabular}

${ }^{*}$ Grade 5=dark staining (greatest amount of antibody); grade 1=light staining (smallest amount of antibody).

the level to denatured type II collagen as compared with the other patients. Also, many patients had antibodies to denatured type II collagen but no antibodies to denatured type XI collagen. These findings suggest that some patients produce antibodies specifically to type XI collagen and that antibodies to type XI collagen are not only antibodies raised to type II collagen which cross react with type XI collagen.

\section{IMMUNOB LOT T ING \\ Rat sera}

The antibodies from the six Wistar rats immunised 14 days previously with native type II collagen showed binding to the $\alpha 1$ (II) chain of type II collagen, and from five rats to the $\alpha 3(\mathrm{XI})$ chain of type XI collagen (Table 3 ). No binding of antibodies to the $\alpha 1(\mathrm{XI})$ or $\alpha 2(\mathrm{XI})$ chains was seen. Normal rat sera showed no binding to any of the chains under these conditions. Similarly sera from 23 other rats (16 Wistar, three DA, two PVG-RT1U, and two $\mathrm{DA} \times$ Wistar cross) immunised in separate experiments with native type II collagen and Freund's incomplete adjuvant also contained antibodies that bound only to the $\alpha 1$ (II) chain of type II collagen and to the $\alpha 3(\mathrm{XI})$ chain of type XI collagen. In general the binding to the $\alpha 1$ (II) chain of type II collagen was stronger than the binding to the $\alpha 3$ (XI) chain of type XI collagen.

The antibodies from the 13 of the 15 Wistar rats immunised with native type XI collagen only showed binding to the $\alpha 2(\mathrm{XI})$ chain of the three chains of type XI collagen with no binding to the $\alpha 1$ (II) chains of type II collagen (Table 3 ). No binding to either collagen could be detected with the other two sera. Thus the immunoblotting technique did not detect the very low levels of antibody to denatured type II collagen seen in these sera using the ELISA technique (Table 1). Sera from three of these rats bled on days 39 and 101 after immunisation also showing binding to the $\alpha 3(\mathrm{XI})$ chain of type XI collagen and to the $\alpha 1$ (II) chain of type II collagen. Sera from seven Sprague Dawley rats which had been immunised with type XI collagen 21 days previously also showed binding only to the $\alpha 2$ (XI) chain of type XI collagen. Again antibodies in the serum of one of these rats bled 50 days after immunisation showed binding also to the $\alpha 3(\mathrm{XI})$ chain of type XI collagen and to the $\alpha 1$ (II) chain of type II collagen, suggesting a change in the specificity of the antibody produced.

\section{Human sera}

Table 4 details the number of patients' sera that showed the presence of antibodies to denatured types II and XI collagens as detected by immunoblotting. About the same number of sera showed binding to type II collagen as were seen in the ELISA (Table 2). A greater number of sera were positive to type XI collagen than in the ELISA, but many of these showed only weak binding (11 sera at grade 1). There was a good correlation between the strength of binding to the $\alpha 1$ (II) chain of type II collagen and the $\alpha 3(\mathrm{XI})$ chain of type XI collagen $(\varrho=0.9108)$, suggesting that these were either the same antibodies binding to similar epitopes on each molecule or that patients producing antibodies to type II collagen also tended to produce antibodies to type XI collagen. Sixteen patients also had antibodies to the $\alpha 2(\mathrm{XI})$ chain of type XI collagen (Table 4), and in these patients there was a strong

Table 4 Binding of antibodies from the 46 sera of patients with RA to the a chains of types II and XI collagen detected by immunoblotting

\begin{tabular}{|c|c|c|c|c|c|c|c|}
\hline & \multicolumn{5}{|c|}{ Grade* } & \multicolumn{2}{|c|}{ Total No } \\
\hline & 5 & 4 & 3 & 2 & 1 & $+v e$ & $-v e$ \\
\hline Type II $\alpha$ chains & 3 & 8 & 10 & 12 & 8 & 41 & 5 \\
\hline Type XI $\alpha 3(X I)$ chain & 2 & 6 & 10 & 8 & 11 & 37 & 9 \\
\hline Type XI $\alpha 2(X I)$ chain & 0 & $\mathbf{0}$ & 2 & 5 & 9 & 16 & 30 \\
\hline Type XI $\alpha 1(\mathrm{XI})$ chain & 0 & 1 & 0 & 1 & 1 & 3 & 43 \\
\hline
\end{tabular}

${ }^{*}$ Grade $5=$ dark staining (greatest amount of antibody); grade $1=$ light staining (smallest amount of antibody). 
correlation between the strength of binding to the $\alpha 2(\mathrm{XI})$ and to the $\alpha 3(\mathrm{XI})$ chain of type XI collagen $(\varrho=0 \cdot 4350)$. Three patients had antibodies which bound to the $\alpha 1(\mathrm{XI})$ chain of type XI collagen. One of the patients showed very strong binding to the $\alpha 1(\mathrm{XI})$ chain of type XI collagen, and this particular patient had no antibodies to native type II collagen in the ELISA and her antibodies to denatured type II collagen were proportionally lower than those to denatured type XI collagen as compared with the patients generally.

\section{Discussion}

Antibodies that bound to both native and denatured types II and XI collagen were seen in the rats immunised with either of these antigens and in some patients with RA. The $\alpha 1(\mathrm{XI})$ and $\alpha 2(\mathrm{XI})$ chains of type XI collagen are biochemically similar to, but genetically distinct from, the $\alpha 1(\mathrm{~V})$ and the $\alpha 2(\mathrm{~V})$ chains of type $\mathrm{V}$ collagen but have no similarity with the $\alpha 1$ (II) chain of type II collagen. ${ }^{14}$ From its amino acid composition and $\mathrm{CNBr}$ peptide pattern, however, the $\alpha 3(\mathrm{XI})$ chain of type XI collagen is similar to the $\alpha 1$ (II) chain of type II collagen, though it is more highly glycosylated. ${ }^{15}$ Thus one would expect that any antibodies that bound to the $\alpha 1$ (II) chain of type II collagen and also cross reacted with type XI collagen would bind only to the $\alpha 3(\mathrm{XI})$ chain of type XI collagen and that antibodies raised to type XI collagen would only cross react with type II collagen if they bound to the $\alpha 3(\mathrm{XI})$ chain of the type XI collagen. Antibodies to conformational determinants, which are lost on denaturation of the molecules, may also occur.

From the ELISA on the rat sera it seemed that both cross reacting and non-cross reacting antibodies were produced when they were immunised to either type II or type XI collagen. Confirmation for the presence of non-cross reacting antibodies to the denatured collagens was seen by the immunoblotting technique as rats immunised with type XI collagen initially showed the presence of antibodies to the $\alpha 2(\mathrm{XI})$ chain only.

The ELISA on human sera suggested that a proportion of antibodies was raised specifically to type II collagen as some sera showed no binding to type XI collagen. It was not clear, however, whether antibodies specific to type XI collagen were present as all sera with anti-type XI collagen antibodies also had antibodies to type II collagen. The immunoblotting technique showed that antibodies to type XI collagen were present as binding of antibodies to the $\alpha 1(\mathrm{XI})$ and to the $\alpha 2(\mathrm{XI})$ chains of type XI collagen occurred in some patients as well as binding of antibodies to the $\alpha 3(\mathrm{XI})$ chain. It is possible that these could be antibodies raised to type $\mathrm{V}$ that cross react with type XI collagen. This is less likely as type. $\mathrm{V}$ collagen is a minor, but widespread, component of virtually all non-cartilaginous tissues, whereas type XI collagen is present in the cartilage, and this: is tissue that is being broken down in RA.

Thus the ELISA and immunoblotting techniques demonstrated that type XI collagen is immunogenic and that antibodies can be specifically formed to its both in rats and in patients with RA. This finding $\overrightarrow{0}$ has implications for both the rat model of collageninduced arthritis and for the role of antibodies tow collagen in RA.

If antibodies to type II collagen are important in the induction of type II collagen induced arthritis and the arthritis in rats immunised with type $\mathrm{X} / \mathrm{N}$ collagen is induced in a similar manner (that is by antibodies that cross react with type II collagen $)$ then these results suggest that the antibodies re $-\infty$ quired to induce arthritis only bind to a smalp number of common epitopes on the two molecules. The inhibition of type II collagen induced arthritiso can be achieved by intravenous administration of type II collagen before intradermal challenge with this antigen, ${ }^{3}$ and this treatment also suppresses the production of anti-type II collagen antibodies. Si⿱⺈⿵⺆⿻二丨冂刂 larly, administration of type XI collagen intza.o venously before intradermal challenge with typêj] collagen suppresses both the humoral response type II collagen and the induction of arthritis (KM personal observation). Thus further examination os antibodies to common and to unique epitopes of these molecules and their relation to arthritis induction and to cartilage destruction in the rat mas enable a better understanding of the role of these antibodies in patients with RA.

The findings in this paper suggest that antibodies: to unique epitopes as well as to common epitopes of each of the two types of collagen molecule (types If and XI) occur in patients with RA. Some of these antibodies may be important in the development of arthritis in some patients and others may just be markers of existing or potential cartilage destruction Type XI collagen appears to be less widely distribute in cartilage than is type II collagen, with preferentia location around chondrocytes. ${ }^{16} 17$ The chondrocytes. are more pronounced in the deeper zones of articular cartilage, and so antibodies unique to type XI collagen, which do not occur in all patients with RA, may be useful markers of severe cartilage destruction. Also, if the antibodies caused damage to the matrix around the chondrocytes then the viability of the chondrocytes might be affected an lead to further cartilage loss. Thus antibodies to different epitopes on these collagen molecules mas have different roles in rheumatoid arthritis. 
As antibodies unique to type II and unique to type XI collagen occur in some patients with RA then, if these antibodies are pathogenic, any treatment might have to affect the response to both collagens to be effective. The inhibition of type II collagen induced arthritis by type XI collagen (see above) suggests that this may be possible by a common mechanism.

This work was supported by grants from the Arthritis and Rheumatism Council. One of us (IC) was supported by the Bingham Trust. We wish to thank the pathology department at the Devonshire Royal Infirmary, Buxton and Miss Angela Thompson at the Manchester Royal Infirmary for collection of the blood samples and Mrs Doreen Ward for typing the manuscript.

\section{References}

1 Grant M E, Ayad S, Kwan A P L, Bates G P, Thomas J T, McClure $J$. The structure and synthesis of cartilage collagens. In: Glauert A M, ed. The control of tissue damage. Amsterdam: Elsevier, 1988: 3-28.

2 Trentham D E, Townes A S, Kang A H. Autoimmunity to type II collagen: an experimental model of arthritis. J Exp Med 1977; 146: 857-67.

3 Morgan K, Clague R B, Shaw M J, Holt P J L. Native type II collagen-induced arthritis in the rat. I. Incidence and humoral response to collagen. Ann Rheum Dis 1980; 39: 285-90.

4 Stuart J M, Cremer M A, Kang A H, Townes A S. Collagen induced arthritis in rats: evaluation of early immunological events. Arthritis Rheum 1979; 22: 1344-51.

5 Morgan K, Evans H B, Firth S A, et al. $1 \alpha 2 \alpha 3 \alpha$ collagen is arthritogenic. Ann Rheum Dis 1983; 42: 680-3.

6 Morgan K, Clague R B, Shaw M J, Firth S A, Twose T M, Holt P J L. Native type II collagen-induced arthritis in the rat: the effect of complement depletion by cobra venom factor. Arthritis Rheum 1981; 24: 1356-62.

7 Stuart J M, Tomoda K, Yoo T J, Townes A S, Kang A H. Serum transfer of collagen-induced arthritis. II. Identification and localisation of auto-antibody to type II collagen in donor and recipient rats. Arthritis Rheum 1983; 26: 1237-44.

8 Kerwar S S, Gordon S, McReynolds R A, Oronsky A L. Passive transfer of arthritis by purified anticollagen immunoglobulin: localisation of ${ }^{125}$ I-labelled antibody. Clin Immunol Immunopathol 1983; 29: 318-22.

9 Morgan K, Clague R B, Collins I, Ayad S, Phinn S D, Holt $P \mathbf{J}$ L. Incidence of antibodies to native and denatured cartilage collagens (types II, IX, and XI) and to type I collagen in rheumatoid arthritis. Ann Rheum Dis 1987; 46: 902-7.

10 Bitter T, Muir H M. A modified uronic acid carbazole reaction. Anal Biochem 1962; 4: 330-4.

11 Ropes M W. Diagnostic criteria for rheumatoid arthritis. 1958 revision. Ann Rheum Dis 1959; 18: 49-53.

12 Morris N P, Bachinger H P. Type XI collagen is a heterotrimer with the composition $(1 \alpha 2 \alpha 3 \alpha)$ retaining non-triple-helical domains. Journal of Biological Biochemistry 1987;262: 11345-50.

13 Towbin H, Stalhelin T, Gordon J. Electrophoretic transfer of proteins from polyacrylamide gels to nitrocellulose sheets: procedures and some applications. Proc Natl Acad Sci USA 1979; 76: 4350-4.

14 Burgeson R E, Hebda P A, Morris N P, Hollister D W. Human cartilage collagens. Comparison of cartilage collagen with human type V collagen. J Biol Chem 1982; 257: 7852-6.

15 Burgeson R E, Hollister D W. Collagen heterogeneity in human cartilage: identification of several new collagen chains. Biochem Biophys Res Commun 1979; 87: 1124-31.

16 Ricard-Blum S, Hartman D J, Herbage D, Payen-Meyran C, Ville G. Biochemical and immunolocalisation of minor collagens in foetal calf cartilage. FEBS Lett 1982; 146: 343-7.

17 Evans H B, Ayad S, Abedin M Z, et al. Localisation of collagen types and fibronectin in cartilage by immunofluorescence. Ann Rheum Dis 1983; 42: 575-81. 